\title{
The Effect of Grape Seed Extract on Semen Oxidative Stress Markers in Men with Idiopathic Infertility: A Cross-Sectional Before-After Study
}

\author{
Mohammad Soleimani, ${ }^{1}$ and Navid Masoumi ${ }^{1{ }^{1}}{ }^{*}$ \\ ${ }^{1}$ Department of Urology, Shahid Modarress Hospital, Shahid Beheshti University of Medical Sciences, Tehran, Iran \\ "Corresponding author: Navid Masoumi, Saadatabad District, Yadegar Emam Exp. way, Shahid Modarres Hospital, Tehran, Iran. Tel: +98-2122074087-98, Fax: +98-2122074101, \\ E-mail: nmasoumig@gmail.com
}

Received 2017 May 22; Accepted 2017 August 19.

\begin{abstract}
Background: Assisted reproductive technique is the last treatment resort for idiopathic male infertility (IMI). In recent years, antioxidants have received vast attention to treat IMI by decreasing seminal oxidative stress.

Methods: In this cross-sectional before-after study, we evaluated the effects of grape seed extract (GSE) as an antioxidant on seminal chemistry. Twenty-nine patients with IMI were treated with GSE $600 \mathrm{mg}$ per day for 3 months. Seminal catalase, superoxide dismutase and malondialdehyde, and serum FSH, LH, and testosterone levels were evaluated both at the beginning and at the end of the study.

Results: Mean age of the patients was $32.5 \pm 4.9$ years. GSE consumption resulted in increased semen catalase ( $44.67 \pm 17.11 \mathrm{vs.} 53.05$ $\pm 18.6, \mathrm{P}=0.016)$, decreased semen malondialdehyde ( $1.77 \pm 0.48$ vs. $1.55 \pm 0.43, \mathrm{P}=0.024)$, and increased serum FSH ( $3.53 \pm 1.51 \mathrm{vs}$. $4.3 \pm 2.00, \mathrm{P}=0.026)$.
\end{abstract}

Conclusions: Our study revealed GSE effectiveness in decreasing seminal oxidative stress in patients suffering from IMI.

Keywords: Grape Seed Extract, Infertility, Anti-Oxidant

\section{Background}

Male factor infertility is encountered with increased frequency as the sole or contributing factor in infertility of couples seeking medical attention for conception in recent years and it is the main reason for roughly half of all assisted reproductive techniques (ARTs). Infertility with indeterminate cause accounts for $25 \%$ of cases in males $(1,2)$. When the man is diagnosed with idiopathic male infertility, ARTs are one of the last remaining resorts for the couple. Recently, andrologists are focusing mostly on the quality of semen and sperms fertility potential rather than the traditional sperm count in semen analysis (1).

Oxidative stress has gained increased attention as a causal factor of sperm damage and immobility as well as the resultant decrease in semen quality (3-5). Spermatozoa are the first cells found to produce reactive oxygen species (ROS) (6); but leukocytes present in seminal fluid are greater contributors to oxidative stress in semen (5).

A variety of antioxidants has been successfully used in previous studies to improve semen quality (7-9) with different effects on sperm damage and motility.

Grape seed contains many natural antioxidants and has been shown to help protect body against oxidative stress $(10,11)$. Grape products have been shown to protect sperms from oxidative stress in vitro and improve sperm quality in rats (11-14); but they have never been investigated as a therapeutic modality for treatment of male infertility in human.

In this study, we supplemented grape seed extract (GSE) to men suffering from idiopathic male infertility and investigated its effect on the markers of seminal oxidative stress for the first time in humans.

\section{Methods}

We conducted a cross-sectional before-after study on patients referring to Tehran Royan infertility center with the chief complaint of infertility from 2014 to 2016.

Since idiopathic male infertility is a diagnosis of exclusion, patients with any of the following disorders were excluded from the study: any hormonal, anatomic (varicocele, epididymis obstruction, history of epididymitis or orchitis) or congenital abnormality resulting in infertility, any chromosomal abnormality, chronic renal disease (Creatinine $>2$ ), chronic liver disease (liver function tests $>2 \mathrm{x}$ normal), diabetes, infectious disease (fever and leukocytosis) in the past month, alcohol or cigarette use, history of 
drug abuse, treatment with any drug that may affect reproductive hormones or sexual function, any occupation that would affect sexual function, and change in food regimen during the study (e.g. using weight-gain or weightloss programs).

After obtaining the informed consent, two semen and serum samples with one-week interval were taken and analyzed for semen oxidative markers (malondialdehyde, catalase, and superoxide dismutase (SOD)) and serum level of testosterone, LH, and FSH. Subsequently, all participants were treated with GSE capsules containing $300 \mathrm{mg}$ GSE twice a day. Half way through the treatment period (40 50 days), all patients were revisited and inquired about the proper drug consumption and any possible side effects. After 3 months of treatment, all examinations and laboratory tests were repeated.

The grape seed capsule used in this study was prepared at the drug applied research center (Tabriz, Iran). Grape seeds were removed from pulps, dried at $70^{\circ} \mathrm{C}$ for $30 \mathrm{~min}$ utes and grinded. The powder was dissolved in n-Hexane, centrifuged for 30 minutes, and then sieved. This dross was dissolved in methanol, centrifuged for 30 minutes, and sieved 3 more times. The solution (comprised of methanol solvent plus grape seeds extract) was dried at $40^{\circ} \mathrm{C}$. The extract was separated from solvent, collected, and stored in a refrigerator. The antioxidant power of the product was determined by diphenylpicrylhydrazyl procedure as RC50 $=4 \times 10^{3} \mathrm{mg} / \mathrm{mL}$ (15). GSE capsules contained the following ingredients: dicalcium phosphate, gelatin, microcrystalline cellulose, and $300 \mathrm{mg}$ of GSE. Capsules' ingredients were equivalent to 20 - 25 grape seeds. In an analysis we performed on the capsules, they contained at least 95\% of proanthocyanidins and $80 \%$ of polyphenolic compounds.

Evaluation for scavenger antioxidants consisting of semen levels of catalase, superoxide dismutase, and malondialdehyde was carried out using enhanced chemiluminescence technique.

Paired samples t-test was performed to compare before and after results in our group of patients. Data were analyzed using SPSS software (SPSS, Inc., Chicago, IL, USA) and $\mathrm{P}<0.05$ was considered statistically significant.

\section{Results}

In total, 30 patients were recruited. During the course of the study, one patient was lost to follow-up due to not attending the follow-up clinic.

The mean age of the patients was $32.4 \pm 5.1$ and duration of infertility was $4.9 \pm 2.8$ years. After 3 months of treatment, we observed a decrease in semen malondialdehyde $(\mathrm{P}=0.024)$ and an increase in semen catalase ( $\mathrm{P}$ $=0.016)$ levels. They also showed a significant increase in serum FSH levels $(\mathrm{P}=0.026)$ at the end of the treatment period. Detailed comparison of results is summarized in Table 1.

Table 1. Before and After Values and Their Significance in Our Patients

\begin{tabular}{|c|c|c|c|}
\hline \multirow[t]{2}{*}{ Variables } & \multicolumn{3}{|c|}{ GSE } \\
\hline & Before & After & Pvalue \\
\hline \multicolumn{4}{|l|}{ Serum measures } \\
\hline $\mathrm{LH}, \mathrm{U} / \mathrm{L}$ & $2.22 \pm 0.8$ & $2.07 \pm 0.7$ & 0.485 \\
\hline FSH, U/L & $3.53 \pm 1.5$ & $4.30 \pm 2.0$ & $0.026^{\mathrm{a}}$ \\
\hline Testosterone, $\mathrm{nmol} / \mathrm{L}$ & $9.50 \pm 0.81$ & $9.17 \pm 0.73$ & 0.259 \\
\hline \multicolumn{4}{|l|}{ Seminal plasma measures } \\
\hline Malondialdehyde, $\mathrm{nmol} / \mathrm{L}$ & $1.8 \pm 0.1$ & $0.6 \pm 0.4$ & $0.024^{\mathrm{a}}$ \\
\hline Catalase, $\mathrm{U} / \mathrm{mL}$ & $44.7 \pm 17.1$ & $53.1 \pm 18.6$ & $0.016^{\mathrm{a}}$ \\
\hline $\mathrm{SOD}, \mathrm{U} / \mathrm{mL}$ & $3.96 \pm 1.5$ & $3.87 \pm 1.6$ & 0.770 \\
\hline
\end{tabular}

Abbreviations: FSH, Follicle-Stimulating Hormone; LH, Luteinizing Hormone SOD, Superoxide Dismutase.

${ }^{\mathrm{a}}$ Statistically significant.

\section{Discussion}

Our study demonstrated the beneficial effect of an antioxidant medication on semen ROS level, which has been proven as a contributing factor in male infertility. Oxidative stress to spermatozoa, as one of the causes of male infertility, has received vast attention in recent years, and it is shown to involve in $30 \%-80 \%$ of infertile males. Reactive oxygen species (ROS), as direct mediators of oxidative stress, are of utmost importance (16). ROS, consisting of oxygen ions, free radicals, and peroxides, can cause infertility through directly damaging spermatozoa DNA, or impairing spermatozoa plasma membrane integrity, resulting in declined motility and penetrating capability (5, 16). Main sources of ROS in semen are leukocytes and immature spermatozoa (5). Living cells produce ROS by the NADPH oxidase system. The NADPH oxidase pathway by which spermatozoa create ROS (NOX 5) is different from that of leukocytes and it is not controlled by protein kinase C (17). While leukocytes produce a greater amount of ROS, the closer proximity of NOX 5 system to sperm DNA suggests a greater influence on spermatozoa.

Recent accumulative in vitro data suggest that oxidative stress results in sperm lipid peroxidation and DNA damage (18). Furthermore, seminal oxidative stress has been reported to have a positive correlation with sperm DNA damage (19) and impairment of sperm fertilization capacity (20). Higher levels of ROS in infertile men semen 
compared to fertile counterparts support the in vitro data (21).

As an opposing force to oxidative stress, antioxidants are naturally present in seminal fluid, which counteract many adverse effects of ROS. Non-enzymatic antioxidants including ascorbic acid (Vitamin C), alfa-tocopherol (Vitamin E), glutathione, amino acids (taurine, hypotaurine), albumin, carnitine, carotenoids, flavenoids, urate, and prostasomes are part of seminal fluid content. These agents are believed to be principally involved in reducing oxidative stress by neutralization of ROS and preventing sperm damage (5).

Studies conducted on infertile men have postulated lower levels of antioxidants in their semen plasma compared to fertile men (15). Antioxidant supplementation has resulted in improved in vivo DNA quality (22) in infertile men and an improved chance of pregnancy in their partner (23). Grape seed extract, as a potential antioxidant, could be considered in reducing seminal oxidative stress.

Comprising many different chemical compounds, GSE has diverse therapeutic usages. It has been effective in prevention of colorectal cancer (24). DNA protective effects of GSE are suggested to be due to its antioxidant capacities (25). GSE also has anti-inflammatory effects by reducing pro-inflammatory cytokines (26). It also prevents oxidation of low-density lipoprotein cholesterol, improves lipid profile, and helps reduce drug-induced nephrotoxicity (27).

Grapes contain high concentrations of resveratrol, quercetin, catechin, epicatechin, and proanthocyanidins, all of which are potent antioxidants. Grape seed has a higher amount of proanthocyanidins while grape skin is richer in resveratrol. Polyphenolic compounds like flavonoid proanthocyanidins inflict their antioxidant potential by scavenging free radicals and inhibiting lipid peroxidation in vitro and in vivo (27).

Different dosages of GSE have been used in previous studies (100 - 720mg). US national center for complementary and alternative medicine reports that oral supplementation of GSE for up to 8 weeks has been well tolerated in many clinical trials (NCCAM report on GSE) (28). Toxicity of grape seed extract has been investigated in many studies and consumption of different doses of the extract has been proven to be safe except for a possible mutagenic effect at very high doses in rats $(4-5 \mathrm{~g} / \mathrm{kg})(18,44)$. We have used lower doses of GSE on human subjects in our previous studies with no observed adverse effects (27). We decided to use a higher dose of GSE (600 mg/day) in the current study which is still much lower than the doses causing adverse effects in rats. Fortunately, no adverse effects were reported by any of our patients.

Effect of resveratrol in infertility has been investigated in vitro and in rats. In a study investigating the effect of trans-resveratrol supplementation on infertility in rats, daily oral administration of this phytochemical to adult male rats increased serum testosterone and improved sperm count but had no effect on sperm motility (11). In another study, intragastric administration of resveratrol to rats with 2, 5-hexanedione-induced testicular injury resulted in increased expression of c-kit protein and enhanced spermatogenesis (12). In vitro incubation of human sperms with trans-resveratrol could protect sperms chromatin and lipid membrane against induced oxidative stress and could improve their motility (13). Hyperthyroid rats supplemented with resveratrol showed improved sperm motility and decreased lipid peroxidation in their testes compared to controls (14). No study has investigated the effect of grape seed extract or any of its compounds on male infertility.

The decrease in semen malondialdehyde as the marker of oxidative stress and the increase in semen catalase levels following GSE consumption in our patients can be attributed to the antioxidant content of grape seed. The same decrease in oxidative stress markers in semen has been reported after multiple compounds, e.g.; Vitamin A, vitamin C, vitamin E, selenium, glutathione, N-acetylcysteine, and carnitine (7-9).

While we tried our best to take into account every possible confounding factor and to control patients' compliance with their therapy, one patient was lost to follow-up during the course of study. We performed detailed analysis of the seminal antioxidant status but the ultimate goal of any infertility therapy is conception, which was not included as a final result in our investigation. Larger studies with longer follow-up that could take into account the conception as the final result may help further establish the beneficial effects of this naturally available antioxidant on male infertility.

\subsection{Conclusion}

The results of the present study suggest the possible beneficial effect of GSE on decreasing seminal oxidative stress in infertile men. One-third of men with infertility problems already take antioxidant supplements, demonstrating their acceptance of natural therapies. GSE supplementation, in conjunction with the standard therapy, could help improve the chance of conception in infertile men especially if they have evidence of oxidative stress.

\section{Footnote}

Conflicts of Interests: The authors declare that they have no conflicts of interest regarding this manuscript. 


\section{References}

1. Rocchietti March M, Isidori A. New frontiers in the treatment of male sterility. Contraception. 2002;65(4):279-81. doi: 10.1016/S00107824(02)00296-2. [PubMed: 12020778].

2. McLachlan RI. Approach to the patient with oligozoospermia. $J$ Clin Endocrinol Metab. 2013;98(3):873-80. doi: 10.1210/jc.2012-3650. [PubMed: 23472228].

3. Agarwal A, Nallella KP, Allamaneni SS, Said TM. Role of antioxidants in treatment of male infertility: an overview of the literature. Reprod Biomed Online. 2004;8(6):616-27. doi: 10.1016/S1472-6483(10)61641-0. [PubMed: 15169573].

4. Doshi SB, Khullar K, Sharma RK, Agarwal A. Role of reactive nitrogen species in male infertility. Reprod Biol Endocrinol. 2012;10:109. doi: 10.1186/1477-7827-10-109. [PubMed: 23241221].

5. Tremellen K. Oxidative stress and male infertility-a clinical perspective. Hum Reprod Update. 2008;14(3):243-58. doi: 10.1093/humupd/dmn004. [PubMed:18281241].

6. Griveau JF, Le Lannou D. Reactive oxygen species and human spermatozoa: physiology and pathology. Int J Androl. 1997;20(2):61-9. doi: 10.1046/j.1365-2605.1997.00044.x. [PubMed: 9292315].

7. Vicari E, La Vignera S, Calogero AE. Antioxidant treatment with carnitines is effective in infertile patients with prostatovesiculoepididymitis and elevated seminal leukocyte concentrations after treatment with nonsteroidal anti-inflammatory compounds. Fertil Steril. 2002;78(6):1203-8. doi: 10.1016/s0015-0282(02)04350-9.

8. Lenzi A, Lombardo F, Sgro P, Salacone P, Caponecchia L, Dondero F, et al. Use of carnitine therapy in selected cases of male factor infertility: a double-blind crossover trial. Fertil Steril. 2003;79(2):292-300. doi: 10.1016/S0015-0282(02)04679-4. [PubMed: 12568837].

9. Keskes-Ammar L, Feki-Chakroun N, Rebai T, Sahnoun Z, Ghozzi H, Hammami S, et al. Sperm oxidative stress and the effect of an oral vitamin $\mathrm{E}$ and selenium supplement on semen quality in infertile men. Arch Androl. 2003;49(2):83-94. doi: 10.1080/01485010390129269. [PubMed: 12623744].

10. Bagchi D, Bagchi M, Stohs SJ, Das DK, Ray SD, Kuszynski CA, et al. Free radicals and grape seed proanthocyanidin extract: importance in human health and disease prevention. Toxicology. 2000;148(2-3):187-97. doi: 10.1016/S0300-483X(00)00210-9. [PubMed: 10962138].

11. Juan ME, Gonzalez-Pons E, Munuera T, Ballester J, Rodriguez-Gil JE, Planas JM. trans-Resveratrol, a natural antioxidant from grapes, increases sperm output in healthy rats. J Nutr. 2005;135(4):757-60. [PubMed: 15795430].

12. Jiang YG, Peng T, Luo Y, Li MC, Lin YH. Resveratrol reestablishes spermatogenesis after testicular injury in rats caused by 2, 5-hexanedione. Chin Med J (Engl). 2008;121(13):1204-9. [PubMed: 18710639].

13. Collodel G, Federico MG, Geminiani M, Martini S, Bonechi C, Rossi C, et al. Effect of trans-resveratrol on induced oxidative stress in human sperm and in rat germinal cells. Reprod Toxicol. 2011;31(2):239-46. doi: 10.1016/j.reprotox.2010.11.010. [PubMed: 21126573].

14. Ourique GM, Finamor IA, Saccol EM, Riffel AP, Pes TS, Gutierrez K, et al. Resveratrol improves sperm motility, prevents lipid peroxidation and enhances antioxidant defences in the testes of hyperthyroid rats. Reprod Toxicol. 2013;37:31-9. doi: 10.1016/j.reprotox.2013.01.006. [PubMed: 23391542].
15. Garrido N, Meseguer M, Simon C, Pellicer A, Remohi J. Pro-oxidative and anti-oxidative imbalance in human semen and its relation with male fertility. Asian J Androl. 2004;6(1):59-65. [PubMed: 15064836].

16. Agarwal A, Prabakaran S, Allamaneni S. What an andrologist/urologist should know about free radicals and why. Urology. 2006;67(1):2-8. doi 10.1016/j.urology.2005.07.012. [PubMed:16413322].

17. Sabeur K, Ball BA. Characterization of NADPH oxidase 5 in equine testis and spermatozoa. Reproduction. 2007;134(2):263-70. doi 10.1530/REP-06-0120. [PubMed: 17660236].

18. Kemal Duru N, Morshedi M, Oehninger S. Effects of hydrogen peroxide on DNA and plasma membrane integrity of human spermatozoa. Fertil Steril. 2000;74(6):1200-7. doi: 10.1016/S0015-0282(00)015910. [PubMed: 11119751]

19. Moustafa MH, Sharma RK, Thornton J, Mascha E, Abdel-Hafez MA Thomas AJ, et al. Relationship between ROS production, apoptosis and DNA denaturation in spermatozoa from patients examined for infertility. Hum Reprod. 2004;19(1):129-38. doi: 10.1093/humrep/deh024. [PubMed: 14688171].

20. Jedrzejczak P, Fraczek M, Szumala-Kakol A, Taszarek-Hauke G, Pawelczyk L, Kurpisz M. Consequences of semen inflammation and lipid peroxidation on fertilization capacity of spermatozoa in in vitro conditions. Int J Androl. 2005;28(5):275-83. doi: 10.1111/j.13652605.2005.00547.x. [PubMed: 16128987].

21. Agarwal A, Sharma RK, Nallella KP, Thomas AJ, Alvarez JG Sikka SC. Reactive oxygen species as an independent marker of male factor infertility. Fertil Steril. 2006;86(4):878-85. doi: 10.1016/j.fertnstert.2006.02.111. [PubMed: 17027357]

22. Menezo YJ, Hazout A, Panteix G, Robert F, Rollet J, Cohen-Bacrie P, et al. Antioxidants to reduce sperm DNA fragmentation: an unexpected adverse effect. Reprod Biomed Online. 2007;14(4):418-21. doi 10.1016/S1472-6483(10)60887-5. [PubMed: 17425820].

23. Tremellen K, Miari G, Froiland D, Thompson J. A randomised control trial examining the effect of an antioxidant (Menevit) on pregnancy outcome during IVF-ICSI treatment. Aust $\mathrm{N} \mathrm{Z} \mathrm{J} \mathrm{Ob-}$ stet Gynaecol. 2007;47(3):216-21. doi: 10.1111/j.1479-828X.2007.00723.x. [PubMed: 17550489].

24. Nomoto H, Iigo M, Hamada H, Kojima S, Tsuda H. Chemoprevention of colorectal cancer by grape seed proanthocyanidin is accompanied by a decrease in proliferation and increase in apoptosis. Nutr Cancer. 2004;49(1):81-8. doi:10.1207/s15327914nc4901_11. [PubMed:15456639].

25. Balu M, Sangeetha P, Murali G, Panneerselvam C. Modulatory role of grape seed extract on age-related oxidative DNA damage in central nervous system of rats. Brain Res Bull. 2006;68(6):469-73. doi 10.1016/j.brainresbull.2005.10.007. [PubMed:16459205].

26. Terra X, Valls J, Vitrac X, Merrillon JM, Arola L, Ardevol A, et al. Grapeseed procyanidins act as antiinflammatory agents in endotoxinstimulated RAW 264.7 macrophages by inhibiting NFkB signaling pathway.J Agric Food Chem. 2007;55(11):4357-65. doi:10.1021/jfo633185. [PubMed: 17461594].

27. Razavi SM, Gholamin S, Eskandari A, Mohsenian N, Ghorbanihaghjo A, Delazar A, et al. Red grape seed extract improves lipid profiles and decreases oxidized low-density lipoprotein in patients with mild hy perlipidemia. J Med Food. 2013;16(3):255-8. doi:10.1089/jmf.2012.2408. [PubMed: 23437789].

28. National Center for Complementary and Alternative Medicine (NC CAM) . Herbs at a glance: Grape Seed Extract Available from: http: //nccam.nih.gov/health/grapeseed/ataglance.htm. 